\title{
INCORPORATING HETEROGENEITY OF TRAVELERS' PREFERENCES INTO THE OVERALL HOSTEL PERFORMANCE RATING
}

\author{
Marija Kuzmanović ${ }^{*}$ and Milena Vukić ${ }^{2}$ \\ ${ }^{1}$ University of Belgrade, Faculty of Organizational Sciences, Belgrade, Serbia; \\ ${ }^{2}$ The College of Hotel Management in Belgrade, Belgrade, Serbia;
}

Received: 4 February 2021;

Accepted: 27 June 2021;

Available online: 12 July 2021.

\begin{abstract}
Original scientific paper
Abstract: Hostels have become a very popular form of accommodation and their varieties have grown steadily in recent years. To ensure the sustainability of this business model, it is necessary to understand the main drivers influencing travelers to choose a hostel accommodation. For this purpose, we conducted an online survey using convenience sampling and purposive sampling techniques. Respondents' preferences to six hostel attributes (cleanliness, location, staff, atmosphere, facilities, and cancellation policy) were determined using discrete choice analysis. Sample results showed that the most important attributes are cleanliness and location, while the atmosphere is the least important one. However, widespread heterogeneity in preferences was observed, and cluster analyzes identified three distinct groups of travelers: "cleanliness sticklers", "location demanders" and "party seekers". Facilities and atmosphere were found to be very important attributes for particular clusters. These findings can help design a marketing strategy for each of the identified segments to ensure sustainable business. Finally, we have proposed a new approach to calculating the hostel overall rating based on attribute importance, which shows much better discriminatory power compared to the traditional average-based approach.
\end{abstract}

Key words: Hostel; discrete choice analysis; attribute importance scores; preference-based clustering; simulation; weighted performance rating.

\section{Introduction}

Over the last six decades, tourism industry become one of the largest economic sectors in the world (Mihalic, 2014). The importance of the tourism industry is evident in both developed and developing countries, which is best reflected through a number of direct and indirect impacts on national economies (World Travel and Tourism * Corresponding author.

$$
\text { E-mail addresses: marija.kuzmanovic@fon.bg.ac.rs (M. Kuzmanovic), }
$$


Incorporating heterogeneity of travelers' preferences into the overall hostel performance...

Council, 2018). Further strong growth of the tourism industry around the world was expected, but the appearance of the COVID-19 pandemic temporarily hindered it. Farr (2020) states that after the end of the pandemic, it will take about 18 to 24 months for daily tourist activities to return to the level before the pandemic (Nguyen, 2020).

The structure of the tourism market has changed significantly and continues to change over the years, with increasing attention paid to the concept of sustainability and related topics such as circular economy, collaborative consumption, sharing economy, and low-income consumers targeting (Lemus-Aguilar et al., 2019). The development of the Internet has significantly contributed to these trends. Nowadays, tourists have access to more information, they are more mobile, and are more willing to experiment with unconventional forms of travel. The expansion of low-cost airlines has increased the number of both available destinations and flights between the two destinations, leading to further price reductions due to growing competition. A study carried out by Eugenio-Martin and Inchausti-Sintes (2016) shows that savings achieved by low-cost transportation are at least partially transferred to spending on the destination itself. Positive changes are also noticeable in low-budget accommodations such as hostels, which show more online penetration than hotels and apartment rentals (Muñoz-Fernández et al., 2016). Despite the outbreak of the COVID19 pandemic in 2020 that negatively affected various industries, including tourism, travelers are expected to travel again, and their demands will affect the future of affordable accommodation. Accordingly, hostels must be prepared to respond to these demands in the right way.

Although initially the cost of accommodation was the main reason for travelers to choose hostels, over the years, the type of hostel guests changed and their motives and preferences became more diverse. To increase guest satisfaction, some hostels have launched a number of specific services such as self-serving facilities, group social and sports activities, the ability to rent certain equipment. Some hostels have recognized the importance of environmental sustainability and are taking action to promote such activities. The development of technology and digitization made it possible for different hostel visitors to exchange impressions and accommodation reviews. On the one hand, this provides the guests with a certain level of security when choosing an accommodation and helping them find accommodations that match their desires. Hostel owners, on the other hand, receive feedback from their clients and can eliminate potential weaknesses on time, as in the Internet era only a few negative reviews can have serious consequences on business success (Martins et al., 2018).

The fact is that hostels have become very attractive to investors in recent years, that their number and varieties are constantly growing, and that even more prosperity is expected in the future through improvement of product quality and product offer offerings. In such a competitive environment, the concept of sustainability becomes crucial. Unlike traditional entrepreneurship, which focuses mainly on economic development, sustainable entrepreneurship and sustainable business models aim to balance economic, social and environmental goals (Belz \& Binder, 2017).

In this study, we focus on the key factors influencing hostel guests' satisfaction, which is closely related to the economic and social dimension of sustainable business. We sought to identify individuals' preferences for key hostel characteristics, identify the most important factors that influence their decision when choosing a hostel, and investigate whether these factors depend on the demographics of the respondents or their habits and attitudes. For that purpose, in this study Discrete Choice Analysis (DCA) was employed. DCA is an approach for identifying the relative importance of attributes when the individuals choose between comparable products or services based on specific features. It has been successfully used for the analysis of individual 
choice behavior in many fields such as economics, marketing, education, transportation, environmental management, and healthcare (Rakotonarivo et al., 2016; Popović et al., 2018; Kuzmanovic et al., 2020). It has been applied also in the tourism industry, but primarily to determine guests' preferences and willingness to pay for a hotel room attributes and preferences towards tourist destination (Capitello et al., 2017; Chang et al., 2018; González et al., 2018; Kim \& Park, 2017; Oppewal et al., 2015; Vukic et al., 2015). However, so far DCA has not been used to identify the tradeoffs that respondents are willing to make when it comes to different factors that affect their choice of hostel. Furthermore, using DCA it is possible to identify whether the guests' preferences are heterogeneous, but also to calculate the real overall hostel rating, taking into account that not all factors are equally relevant to certain groups of guests. If there are differences in factors that affects the satisfaction of guests, hostel owners need to customize their offer to satisfy all guests.

The rest of the paper is organized as follows. Section 2 provides a literature review on hostel specifics and key hostel features that influence travelers' choices. Section 3 covers the study methodology i.e. overview of theoretical foundation of discrete choice modelling is outlined and design of present study is presented. The results of empirical study are given in Section 4. Both aggregated and segment level preferences are presented as well as simulation results. Finally, Section 5 provides concluding remarks and implications for further research.

\section{Literature Review}

The hostel is a short-term accommodation, which focuses particularly on visitors who are most often referred to as backpackers (O'Regan, 2010). Nevertheless, there is no precise definition of this type of accommodation. Some discussion on this issue can be found in scientific literature (Hory et al., 2017; Oliveira-Brochado \& Gameiro, 2013). Difficulties in clear definition appear as a consequence of the global expansion of the spectrum of tourists and their heterogeneous demands.

There are many ways in which the hostel business can contribute to the economic and social sustainability of areas, regions or countries. Hostels are usually associated with people who are traveling on a tight budget and who do not mind to give up their privacy for the sake of lower cost accommodation. World trends and the financial crisis have led to hostels now attracting families and people on a business trip that is constrained by a relatively modest budget (Cave et al., 2008). Thus, one of the basic characteristics of the hostel is that it has to be budget-oriented. Although budget tourists tend to spend less on a daily basis, their travel is generally extended, and total expenditures during their stay are often significantly higher than those of average tourists. Moreover, hostel accommodation businesses in small cities where there are no hotels, contributing significantly to local economic development.

A hostel typically has a more casual atmosphere than hotels and it is more adventure oriented, attracting the younger segment of travelers (de Oliveira Santos, 2016). Hostels offer two types of accommodation, either shared rooms where individual travelers can book a single bed or private rooms with bathrooms when it comes to modern variants of hostels. Consequently, they generally provide more and better opportunities for travelers who are staying in the short term to meet new people from different cultures, by virtue of shared facilities and a common rooms, such as living room, lounge, shower, and kitchen (Lima \& Vicente, 2017). When it comes to the atmosphere and character of the hostel, the one of the famous hostel booking websites, Hostelbookers, provides description of several different types of hostels 
Incorporating heterogeneity of travelers' preferences into the overall hostel performance...

(Oliveira-Brochado \& Gameiro, 2013): (a) 'family hostels', offering clean and comfortable low budget rooms in order to attract families; (b) 'Activity hostels' focusing on providing a wide range of activities to their guests, such as surfing, skiing, hiking, biking etc.; (c) 'Party hostels' designed for travelers who want to have fun and to experience the city's nightlife. These hostels do not have a police time, usually have a bar and organize parties.

Recently, a new type of hostel guests have been appeared, so called 'flashpackers', traveling with a higher budget, often using social media, and have a greater demand for comfort, quality and privacy than the backpackers (Hory et al., 2017). Flashpackers want the backpacking experience with the luxury of a comfortable hotel. While they want the friendly atmosphere, they also want some quiet downtime. An increasing number of such type of travelers steadily increases quality requirements towards the physical features of hostels, leading to a new type of hostel, the so-called 'flashpacking hostels'.

Numerous studies have been conducted, both qualitative and quantitative, for determining the motives, factors and preferences of travelers towards hotels and hostels (Lin et al., 2018; Roy et al., 2019; Puška et al., 2021). As expected, the main features of the hostel, a favorable accommodation price and value for money, have proven to be an important source of customer satisfaction (Nash et al., 2006; Lima \& Vicente, 2017; de Oliveira Santos, 2016; Cró \& Martins, 2017; Veríssimo \& Costa, 2018). However, Hecht and Martin (2006) find out that service preferences vary depending on the three key demographic categories: gender, age, and country of origin. In addition to the accommodation price, most studies emphasize two more hostel features, cleanliness and location, as very important factors that influence the guests' choice as well as their satisfaction (Hecht \& Martin, 2006; Nash et al., 2006; Brochado et al., 2015; Lima \& Vicente, 2017; Martins et al., 2018; Oliveira-Brochado \& Gameiro, 2013; Cró \& Martins, 2017; Amblee, 2015). Studies have also identified some other important tangible factors that increase the satisfaction of guests such as selfserving facilities and the possibility of renting certain equipment (Nash et al., 2006; Brochado et al., 2015; Musa \& Thirumoorthi, 2011; Oliveira-Brochado \& Gameiro, 2013; Veríssimo \& Costa, 2018). Furthermore, the results show that hostel guests want to socialize, to participate in activities and events, to have local experiences and to feel at home (Hecht \& Martin, 2006; Brochado et al., 2015; Martins et al., 2018; Ban et al., 2019). This especially holds for young people (Muñoz-Fernández et al., 2016) and Millennials (Veríssimo \& Costa, 2018). Lima and Vicente (2017) revealed that the main drivers of the overall satisfaction of younger guests are staff's competence and friendliness. Musa and Thirumoorthi (2011) found that politeness and friendliness, commitment, readiness to help and relevant knowledge are very important characteristics of a good staff. Chitty et al. (2007) show that the brand image is a strong predictor of satisfaction of the low-budget guests with the hostel. Cró and Martins (2017) used a hedonic prices and guests' reviews to analyze the impact of the country's crime index on hostel accommodation prices and concluded that guests are willing to pay a higher price if a hostel has higher security and cleanliness level but also good location. Similar conclusions were made by Amblee (2015) who used a word-of-mouth approach.

The most popular booking websites provide the opportunity for hostel guests to evaluate their satisfaction with accommodation on a variety of factors, primarily those that have been also identified as important through scientific literature. Table 1 shows a list of factors that are usually evaluated on certain websites. 
M. Kuzmanović et al./Decis. Mak. Appl. Manag. Eng. 4 (2) (2021) 200-224

Table 1. Overview of guest satisfaction factors on hostel booking websites

\begin{tabular}{c|ccccc}
\hline & $\begin{array}{c}\text { Hostelworld. } \\
\text { com }\end{array}$ & $\begin{array}{c}\text { Hostelbookers. } \\
\text { com }\end{array}$ & $\begin{array}{c}\text { Hostels.c } \\
\text { om }\end{array}$ & $\begin{array}{c}\text { Hostelz.c } \\
\text { om }\end{array}$ & $\begin{array}{c}\text { Booking.c } \\
\text { om }\end{array}$ \\
\hline Location & $\checkmark$ & $\checkmark$ & $\checkmark$ & $\checkmark$ & $\checkmark$ \\
Cleanliness & $\checkmark$ & $\checkmark$ & $\checkmark$ & $\checkmark$ & $\checkmark$ \\
Staff & $\checkmark$ & $\checkmark$ & $\checkmark$ & $\checkmark$ & $\checkmark$ \\
$\begin{array}{c}\text { Safety/Secu } \\
\text { rity }\end{array}$ & $\checkmark$ & $\checkmark$ & $\checkmark$ & $\checkmark$ & \\
Atmosphere & $\checkmark$ & & & & \\
Value/Price & & $\checkmark$ & $\checkmark$ & $\checkmark$ & \\
Facilities & $\checkmark$ & $\checkmark$ & $\checkmark$ & & $\checkmark$ \\
Comfort & & & $\checkmark$ & & \\
Services & & & & & $\checkmark$ \\
Character & $\checkmark$ & & & & \\
\hline
\end{tabular}

\section{Materials and Methods}

\subsection{Discrete Choice Analysis}

Discrete Choice Analysis (DCA), often referred to as a choice-based conjoint analysis, is one of the most commonly used research techniques that helps reveal how individuals make choices and what they really value in products and services. Instead of asking respondents what features they find most important, in discrete choice experiment, respondents are expected to choose between the concepts carefully assembled into choice sets. These concepts are potential real or hypothetical alternatives described by the most relevant tangible and intangible characteristics or attributes (Ben-Akiva et al., 2019).

DCA is theoretically grounded in random utility theory (RUT) and relies on the assumptions of economic rationality and utility maximization (Ben-Akiva \& Lerman, 1985; Mangham et al., 2009), but also assumes heterogeneity in decision-maker and choice alternatives (Oppewal et al., 2015). The output from discrete choice analysis is a measure of utility scores that are numerical values that weight how each attribute and level attribute affected customer's decision to make that choice.

There are five main steps in the process of discrete choice analysis: (1) the identification of key attributes and specification of their levels, (2) creation of the design of experiment, (3) data collection, (4) the choice model estimation, and (5) post-hoc segmentation.

\subsection{Identification of Hostels Attributes and Levels}

At this stage of the research, the identification of characteristics that differentiate a certain set of hostels from others was done. Five attributes have been identified based on the literature review: Location, Staff, Atmosphere, Cleanliness level and Facilities. The appropriate levels have been assigned to these attributes (Table 2).

In addition, the attribute Cancellation policy (refund) was also included in the survey. The need to include this attribute in the study was based on an analysis of the impressions guests leave on TripAdvisor, the world's largest travel portal, as well as on the hostels' websites. Namely, it was noted that one of the most frequent reasons why the guests complain is precisely the problem of refunding money in case of cancellation. This problem comes from three reasons. The first is that hostel reservations are made in about $80 \%$ of cases by means of internet platforms that have 
Incorporating heterogeneity of travelers' preferences into the overall hostel performance...

their own cancellation policy that has priority over the policy of hostel itself. The other is that these platforms see the cancellation as an opportunity to make additional profits, so they charge it as a special service, and the third reason is the insufficiently transparent policy of cancellation. Two levels of attribute have been identified: deposit only and no refunds. The former means that if the guest cancel the reservation on time (usually 1-7 days before the start of the stay, depending on the hostel), the deposit will be refunded, while no refund option mean that the hostel retains the entire amount of the reservation.

Table 2. Attributes and levels used in the study

\begin{tabular}{cc}
\hline Attribute & Levels \\
\hline \multirow{2}{*}{ Location } & City center \\
& Good connection to city center \\
Poor connection to city center
\end{tabular}

Although crucial factor, the price of accommodation has not been included in the list of attributes in this research since prices generally varies from city to city and therefore are not comparable.

\subsection{Experimental Design}

The next stage in discrete choice analysis is to decide which scenarios to present to individuals, i.e. to generate experimental design. Based on selected attributes and attribute levels, a fractional factorial choice design was created. The design is efficient in terms of D-efficiency criteria and supports measurement of two-way interactions. In the cases when such designs are very complex and consist of a large number of choice tasks, so called blocked designs are often used. Blocks are partitions of the choice tasks in the design of experiment that contain a limited number of choice questions for each respondent.

In our study, an experimental design with 22 choice tasks was partitioned into two blocks so that each respondent evaluated only 11 choice tasks. Each choice task consisted of three full profile alternatives (Hostel 1, Hostel 2 and Hostel 3) and one "none of the above" option. Each respondent evaluated a total of 33 alternatives. In this way, the survey covered a total of $66(11 \times 3 \times 2)$ profiles from the possible 648 $(=34 \times 4 \times 2)$. The example of choice task used in survey is given on Figure 1 . 
Which of the following Hostels would you choose?

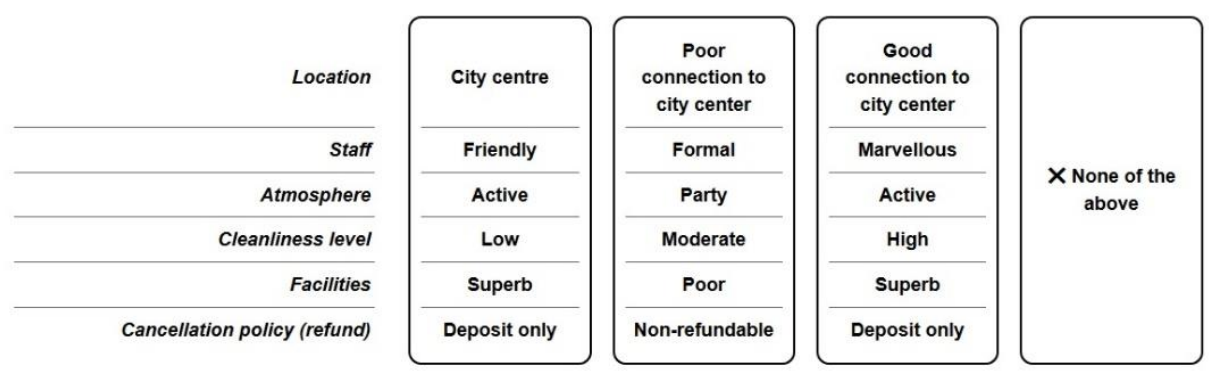

Figure 1. The example of the choice task

\subsection{Study Implementation}

Because DCA calculates preferences for each single respondent, no large sample is required for the results to be valid. However, the generated experimental design has an influence on the sample size required for the trustworthy results (de Bekker-Grob et al., 2015). According to Orme (2010), the rule of thumb for an acceptable sample size is:

$I \geq \frac{500 \times \text { largest product of levels of any two attributes }}{\text { number of tasks } \times \text { number of alternatives per task }}$,

so the minimum sample size for this study was 182 (i.e. $500 \times(3 \times 4) /(11 \times 3)$ ).

To collect responses from respondents, this study used a web-based survey created on the online platform Conjoint.ly. It has been shown that web-based surveys are more suitable for discrete choice experiments than other forms of surveys for reasons such as ease of use, immediacy, time saving and high response rate (Oppewal et al., 2015). According to the purpose and needs of the research, participants were recruited through convenience sampling and purposive sampling methods. The survey was shared in travel groups on social networks, travel-related forums, but also distributed directly by email. The intent was to effectively select participants who would be willing to provide the most relevant data to answer research questions defined. Such were considered to be individuals who occasionally or frequently travel and stay in hotels, hostels or other paid accommodation.

Our questionnaire consisted of three parts: (1) questions concerning respondent demographics; (2) questions about general respondents' habits and experience regarding accommodation while traveling, and (3) eleven hostel choice tasks. To test the questionnaire, the survey was piloted using a sample of 20 respondents.

\subsection{Estimation of the Choice Model}

Discrete choice model can be derived from utility theory and specifies the probability that an individual chooses a particular hostel, with the probability expressed as a function of observed variables that relate both to the hostel and the individual. As mention before, the assumption is that the individuals tend to maximize utility by choosing those hostel that contain most desirable characteristics. In other words, given the set $J$ of mutually exclusive hostel alternatives, it is assumed that an individual $i(i=1, \ldots, l)$ will choose an alternative $j(j=1, \ldots, f)$ if and only if the overall utility that alternative $j$ provides to him at least equal to those associated with other 
Incorporating heterogeneity of travelers' preferences into the overall hostel performance... alternatives in the same choice set. The choice of the individual $i$ is designated by variables $y_{i j}$ for each alternative $j$ :

$y_{i j}=\left\{\begin{array}{cc}1, & U_{i j}>U_{i m}, \quad \forall j \neq m \\ 0, & \text { otherwise }\end{array}\right.$

where $U_{i j}$ represents overall utility and can be expressed as:

$U_{i j}=V_{i j}+\varepsilon_{i j}$.

Random or stochastic component $\varepsilon_{i j}$ represents the unobserved sources of utility related to the characteristics of the individuals and/or hostel attributes and can represent both variations in preferences among population members and measurement errors. The deterministic component of utility, $V_{i j}$, is usually a linear additive model that maps the multidimensional attribute vector into the overall utility (Kuzmanovic et al., 2020):

$V_{i j}=\sum_{k=1}^{K} \sum_{l=1}^{L_{k}} \beta_{i k l} x_{j k l}$

where $\beta_{i k l}$ is partial utility that respondent $i$ attaches to lth level of attribute $k$, socalled part-worth, and $x_{j k l}$ is a binary variable that equals 1 if hostel $j$ contains level $l$ of attribute $k$, otherwise it equals 0 . Accordingly, the probability that individual $i$ would choose hostel $j$ from a set of three mutually exclusive hostels is given by:

$P_{i j}=\frac{\exp \left(U_{i j}\right)}{\sum_{j=1}^{3}\left(\exp \left(U_{i j}\right)\right)}$

Hierarchical Bayes (HB) approach can be used to estimate the parameters in model (4). HB models are hierarchical models analyzed by Bayesian methods, which assume that probability is operationalized as a degree of belief, rather than frequencies as it is in classical statistics (Rossi et al., 2012). The value of the HB model lies in its ability to describe heterogeneity in preferences while retaining its ability to study particular individuals. Besides that, this approach allows more parameters to be estimated with less data collected from each respondent.

Estimated part-worths reflect how strongly that level influences the decision to choose the hostel. Attributes with a large range of influence are consider more important. Accordingly, relative importance of each attribute for each respondent are calculated by dividing the utility range for each attribute separately with the sum of the utility ranges for all attributes (Vukic et al., 2015):

$W_{i k}=\frac{\max _{l} \beta_{i k l}-\min _{l} \beta_{i k l}}{\sum_{k=1}^{K}\left(\max _{l} \beta_{i k l}-\min _{l} \beta_{i k l}\right)}$.

Individual importance scores can be aggregated for the sample as a whole or for clusters in the case of heterogeneous preferences. In addition to a priori segmentation based on socio-demographic variables, this study employs a post-hoc segmentation approach as well. This approach is expected to be more effective as segments will be isolated based on differences in respondents' preferences (Kuzmanovic \& Savic, 2020). Clustering on individual preferences and behavioral differences has been found to be more robust and stable over time. Clusters that differ in the behavioral drivers can be found using K-means cluster analysis (Norris et al., 2014). 


\section{Results}

\subsection{Sample Characteristics}

Survey was conducted in November 2017. Eligibility criteria were that respondents were 16 or older, and that travel at least once a year, staying in paid accommodation. Of 1522 individuals who approached the survey, 273 fully completed the questionnaire, giving a response rate of $14.22 \%$, out of which 218 questionnaires were valid (79.85\%). Slightly more than half of respondents $(55.96 \%)$ were women. The average age of participants was 28.14 years $(\mathrm{SD}=8.33)$. Over $60 \%$ of respondents had completed at least an undergraduate degree and almost $32 \%$ had a postgraduate degree or higher qualification. The majority of participants were European (76.6\%). Detailed demographics are given in Table 3.

Table 3. Demographic data

\begin{tabular}{c|ccc}
\hline Category & Variable & Number $(\mathrm{n}=218)$ & $(\%)$ \\
\hline Gender & Male & 96 & 43.78 \\
Education & Female & 122 & 55.96 \\
level & High school or equivalent & 71 & 32.57 \\
& Bachelor's degree & 75 & 34.40 \\
& Master's degree & 64 & 29.36 \\
Employment & PhD & 5 & 2.29 \\
status & Other & 3 & 1.38 \\
& Unemployed & 11 & 5.04 \\
& Full time employed & 116 & 53.21 \\
& Part time employed & 18 & 8.26 \\
Average & Student & 49 & 22.48 \\
monthly & Employed students & 14 & 6.42 \\
income & Other & 10 & 4.59 \\
& Up to 300 $€$ & 15 & 6.88 \\
& 300-600 $€$ & 40 & 18.35 \\
Continent of & 600-1000 $€$ & 53 & 24.31 \\
residents & More than 1000 $€$ & 57 & 26.15 \\
& No answer & 53 & 24.31 \\
& Europe & 167 & 76.61 \\
& Asia & 13 & 5.96 \\
& North America & 25 & 11.47 \\
& South America & 5 & 2.29 \\
& Africa & 2 & 0.92 \\
& Australia & 6 & 2.75 \\
\hline \multirow{5}{*}{} & & &
\end{tabular}

The most common accommodation choice is hotel (38.25\%), followed by hostel $(27.65 \%)$ and Airbnb (21.56\%). Bed \& breakfast is the first choice for only $5.5 \%$ of the respondents, while the rest of sample prefer other accommodations.

The primary guests of the hostel are considered to be backpackers, but only $8.72 \%$ of our sample perceived themselves as backpackers; the same percentage of sample considered themselves to be a tourist or traveler (41.28\%), while $8.72 \%$ respondents did not match any of the listed categories. However, the majority of backpackers as the first choice of accommodation listed hostel (57.89\% of all backpackers), while those 
Incorporating heterogeneity of travelers' preferences into the overall hostel performance...

who call themselves tourists are usually opt for hotel accommodation and very rare for hostel (15.56\%). When choosing their accommodation, respondents mostly inform via the Internet (41.74\%) and by word-of-mouth from friends and acquaintances (34.86\%).

Nearly $45 \%$ of respondents usually travel with friends. There is $24.37 \%$ respondents who travel with a partner, and $12.97 \%$ who travel and with a family member, while $16.46 \%$ respondents are usually solo travelers. Respondents rarely stay in hostels for more than 7 nights (only 4.13\%); 18.35\% usually stay between 5 and 7 nights, while more than half of the respondents, $112(51.38 \%)$ in hostels stays 2-4 nights. Among the respondents there were $10.09 \%$ those who usually stay for only one night, as well as those who said they never stayed in hostels. Among 35 respondents $(16.06 \%)$ who never use hostel services there were 9 men and 26 women. Respondents were also asked to indicate the lowest average hostel rating on booking websites, which is necessary to consider the booking accommodation. The distribution of the answers is shown in the Figure 2.

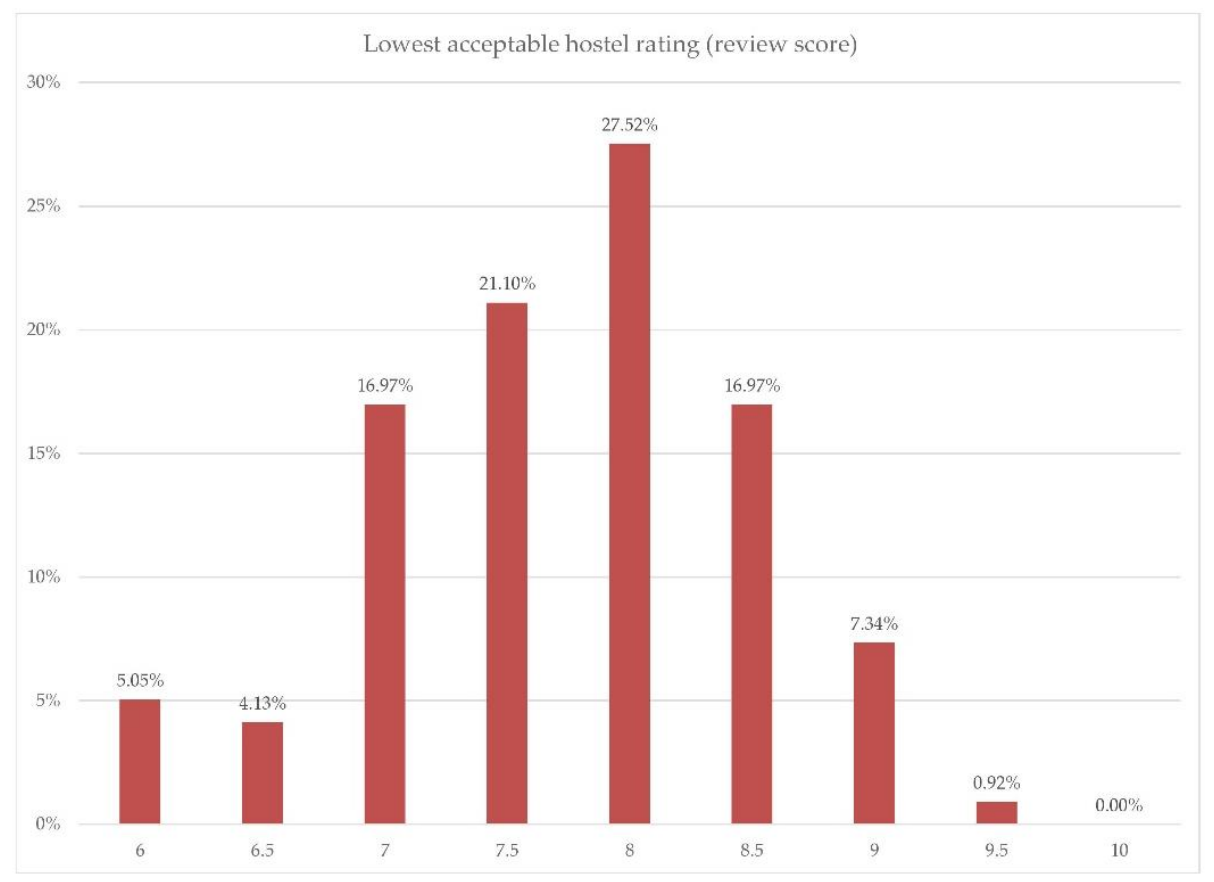

Figure 2. Distribution of the lowest acceptable hostel rating

\subsection{Aggregated Respondents' Preferences}

The primary outputs of DCA are the estimated part-worths (preferences) for various attribute levels. Using HB method, the preferences were estimated for each single respondent, and then averaged for the whole sample (aggregated preferences). Attribute levels have been coded using an effects coding procedure, which constrains the sum of part-worths of each attribute to be zero. Part-worth utilities associated with particular attribute levels provide a deeper insight into which characteristics determine the consumer's choice. The aggregated preferences towards the key hostel characteristics are shown in Table 4. The results indicate a high level of statistical significance for the attribute levels, with all levels having signs in line with a priori 
M. Kuzmanović et al./Decis. Mak. Appl. Manag. Eng. 4 (2) (2021) 200-224

expectations. Namely, negative signs for some levels indicate that respondents considerably less prefer them than those with positive value. For example, respondents do not prefer hostels that have poor connections to the city center (partworth $=-21.44)$, low level of cleanliness $(-19.60)$, or poor offer of facilities $(-7.48)$.

Table 4. Part-worths estimates for the sample

\begin{tabular}{|c|c|c|c|c|c|}
\hline \multirow[t]{2}{*}{ Attribute } & \multirow[t]{2}{*}{ Attribute Level } & \multirow{2}{*}{$\begin{array}{c}\text { Relative } \\
\text { importa } \\
\text { nce }\end{array}$} & \multirow{2}{*}{$\begin{array}{l}\text { Part- } \\
\text { wort } \\
\text { hs }\end{array}$} & \multicolumn{2}{|c|}{$\begin{array}{c}90 \% \\
\text { confidence } \\
\text { interval } \\
\end{array}$} \\
\hline & & & & $\begin{array}{l}\text { Lower } \\
\text { bound }\end{array}$ & $\begin{array}{l}\text { Upper } \\
\text { bound }\end{array}$ \\
\hline \multirow[t]{4}{*}{ Location } & & $33.99 \%$ & & $\begin{array}{c}32.35 \\
\%\end{array}$ & $\begin{array}{c}35.61 \\
\%\end{array}$ \\
\hline & City center & & 12.55 & 11.76 & 13.42 \\
\hline & $\begin{array}{l}\text { Good connection to city } \\
\text { center }\end{array}$ & & 8.89 & 8.26 & 9.55 \\
\hline & $\begin{array}{l}\text { Poor connection to city } \\
\text { center }\end{array}$ & & 21.44 & -22.40 & -20.45 \\
\hline \multirow[t]{4}{*}{ Staff } & & $6.43 \%$ & & $\begin{array}{c}5.52 \\
\%\end{array}$ & $\begin{array}{c}7.23 \\
\%\end{array}$ \\
\hline & Friendly & & 3.03 & 2.60 & 3.38 \\
\hline & Formal & & -3.41 & -3.92 & -2.85 \\
\hline & Marvelous & & 0.38 & 0.01 & 0.78 \\
\hline \multirow[t]{5}{*}{ Atmosphere } & & $3.38 \%$ & & $\begin{array}{c}3.00 \\
\%\end{array}$ & $\begin{array}{c}4.46 \\
\%\end{array}$ \\
\hline & Homely & & 0.93 & 0.65 & 1.19 \\
\hline & Party & & 0.71 & -0.15 & 1.65 \\
\hline & Active & & 0.81 & 0.26 & 1.34 \\
\hline & Traditional & & -2.45 & -2.95 & -2.00 \\
\hline \multirow[t]{4}{*}{$\begin{array}{l}\text { Cleanliness } \\
\text { level }\end{array}$} & & $35.27 \%$ & & $\begin{array}{c}33.91 \\
\%\end{array}$ & $\begin{array}{c}36.35 \\
\%\end{array}$ \\
\hline & Low & & $\begin{array}{c}- \\
19.61\end{array}$ & -20.15 & -18.90 \\
\hline & Moderate & & 3.95 & 3.34 & 4.52 \\
\hline & High & & 15.66 & 14.86 & 16.36 \\
\hline \multirow[t]{4}{*}{ Facilities } & & $12.79 \%$ & & $\begin{array}{c}11.83 \\
\%\end{array}$ & $\begin{array}{c}13.58 \\
\%\end{array}$ \\
\hline & Poor & & -7.48 & -8.01 & -6.87 \\
\hline & Good & & 2.18 & 1.78 & 2.57 \\
\hline & Superb & & 5.30 & 4.81 & 5.67 \\
\hline $\begin{array}{l}\text { Cancellation } \\
\text { policy }\end{array}$ & & $8.15 \%$ & & $\begin{array}{c}7.07 \\
\%\end{array}$ & $\begin{array}{c}9.26 \\
\%\end{array}$ \\
\hline & Deposit only & & 4.07 & 3.53 & 4.61 \\
\hline & Non-refundable & & -4.07 & -4.61 & -3.53 \\
\hline
\end{tabular}

A $90 \%$ confidence interval is also reported under each parameter estimate. It identifies the range in which there is a $90 \%$ probability that the true parameter value falls. For all of the estimated parameters, a zero value fell outside of this $90 \%$ confidence interval, indicating that all independent variables have an influence on the dependent variable at the $90 \%$ level. An additional goodness of fit measure, called 
Incorporating heterogeneity of travelers' preferences into the overall hostel performance...

McFadden's pseudo-R2 provides a measure of how well estimated results describe respondents' answers to the survey. A pseudo-R2 value of $67 \%$ in this survey indicates that the calculated part-worths well describe the respondents' choices (Norris et al., 2014).

The relative importance of the attributes are derived from corresponding partworth utilities and show the extent to which each of the attributes influence the decision of respondents, and which later affects their satisfaction. As it can been seen from Table 4, the most important attributes for the sample as a whole are Cleanliness and Location, with the average importance values of $35.27 \%$ and $33.99 \%$ respectively. Significantly less important is the attribute Facilities (12.79\%), while the Atmosphere is the least important attribute with the average importance of just 3.38\%, indicating that this attribute has almost no influence on the decision about the choice of hostel.

The best-rated hostel concept according to the respondents' preferences is those with a high level of cleanliness, located in the city center, with superb facilities, friendly staff and a homely atmosphere, but also that returns whole amount of deposit in case of cancellation of the reservation.

\subsection{Preferences of Predefined Groups of Respondents}

In order to determine whether the preferences of some predefined groups of respondents were homogeneous, a priori segmentation was performed based on the demographics and habits of the respondents. In particular, the analysis was done on the basis of three variables: (1) the continent of residence, (2) the first choice of accommodation, and (3) gender. Both the partial utilities and the relative importance of the attributes for each subgroup are estimated separately.

As it can be seen from Figure 3, there is no significant differences between the segments in terms of the relative importance attached to the attributes. Furthermore, the order of the levels according associated utilities within all attributes is almost the same, and only slight variations occur within the attribute Atmosphere. Namely, it has been found that males strongly prefer Party hostels, while females prefer a hostel with an active and homely atmosphere, considering party hostels as undesirable for staying. Similarly, respondents who usually stay in hostels give priority to the Party hostels compared to other respondents. However, the Atmosphere is negligible important attribute for all segments, and therefore differences in preferences to certain levels of this attribute have minor impact on the overall preferences. 
M. Kuzmanović et al./Decis. Mak. Appl. Manag. Eng. 4 (2) (2021) 200-224

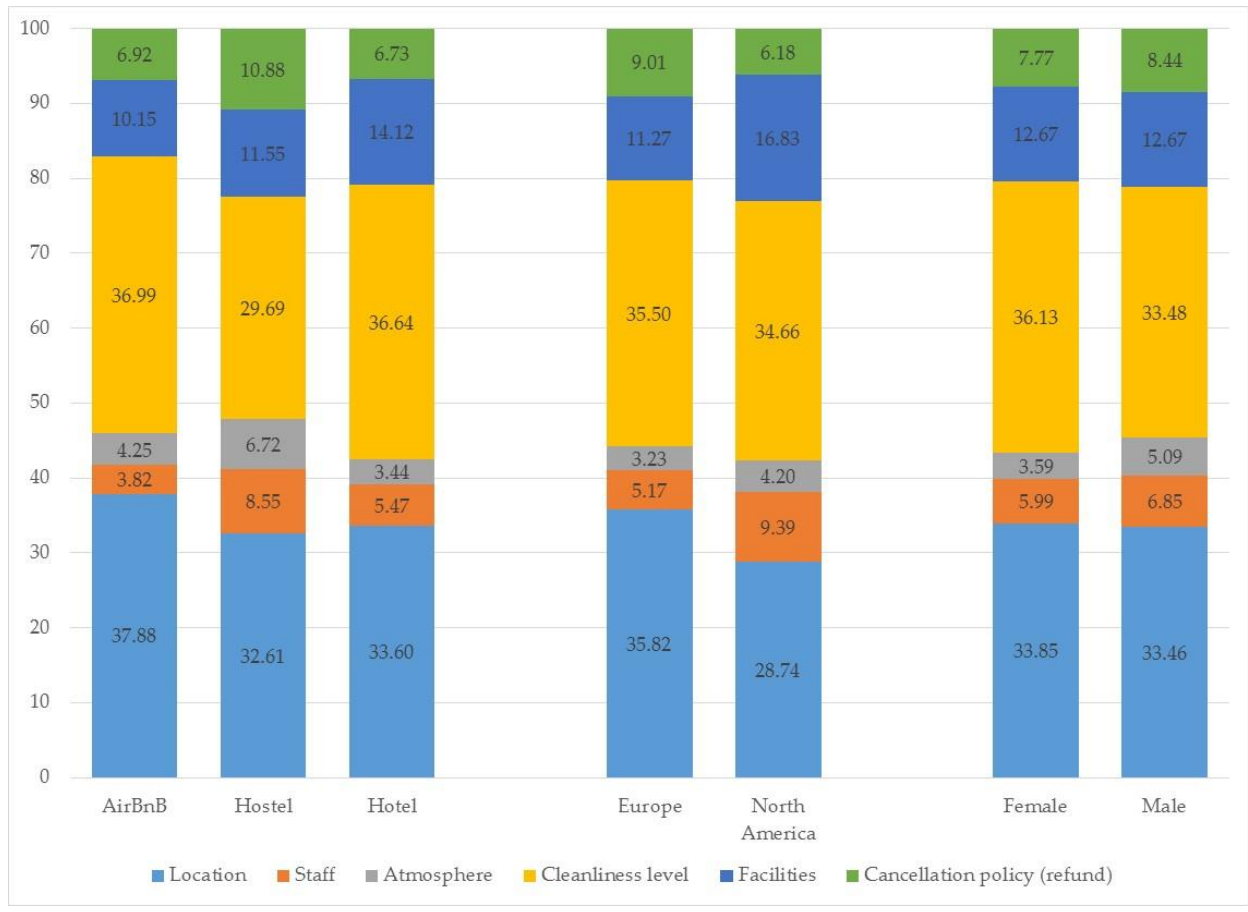

Figure 3. Relative importance of attributes across a priori defined segments (in \%)

\subsection{Preference-based Clustering}

Aggregated results often mask the real situation, so a cluster analysis based on respondents' preference was made. Namely, cluster analysis allows the detection of groups of respondents with homogenous preferences that remain latent in aggregated results. As the preferences are calculated for each respondent individually, preference-based clustering is enabled and for that purpose K-means cluster analysis is employed. Relying on Calinski-Harabasz criteria and the Dunn index, as well as on the bases of knowledge of the market and socio-demographic characteristics of the sample, three clusters were identified. The relative importance of the attributes for each of the clusters are shown in the Table 5, while Figure 4 shows the percentage of inhabitants of certain continents in each of the clusters.

Table 5. Relative importance of the attributes for each of the clusters

\begin{tabular}{c|ccc}
\hline & $\begin{array}{c}\text { Cluster 1 } \\
\text { (Cleanliness } \\
\text { sticklers) }\end{array}$ & $\begin{array}{c}\text { Cluster 2 } \\
\text { (Location } \\
\text { demanders) }\end{array}$ & $\begin{array}{c}\text { Cluster 3 } \\
\text { (Party } \\
\text { seekers) }\end{array}$ \\
\hline Location & $21 \%$ & $45 \%$ & $36 \%$ \\
Staff & $10 \%$ & $2 \%$ & $9 \%$ \\
Atmosphere & $6 \%$ & $4 \%$ & $19 \%$ \\
Cleanliness level & $38 \%$ & $32 \%$ & $21 \%$ \\
Facilities & $19 \%$ & $7 \%$ & $8 \%$ \\
Cancellation policy & $6 \%$ & $10 \%$ & $7 \%$ \\
(refund) & & & \\
\hline
\end{tabular}


Incorporating heterogeneity of travelers' preferences into the overall hostel performance...

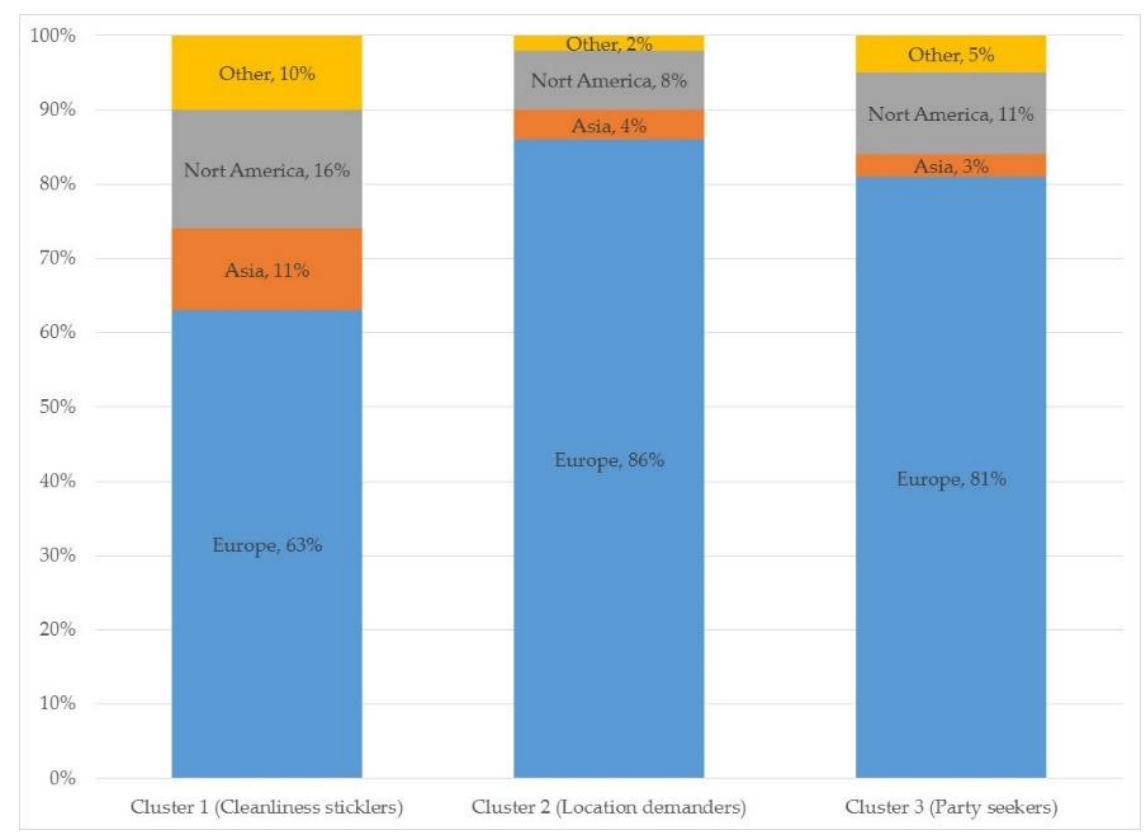

Figure 4. Comparison of clusters concerning the region of respondents' residence

\subsubsection{Cluster 1 - Cleanliness Sticklers}

The first cluster includes slightly more than a third, i.e. 35\% of the total sample. For the respondents from this cluster, the cleanliness is the key decision factor when choosing a hostel (relative importance is 38\%), whereby the respondents prefer only a high level of hostel cleanliness. A moderate level of cleanliness also has a positive sign, but a small value of utility. As it can be seen from Table 5, Location and Facilities also appear as very important attributes, with an importance values of $21 \%$ and $19 \%$ respectively. When it comes to the Location attribute, it can be noted that it is significantly less important than in the average. For the attribute Facilities the opposite applies; this is the only cluster that attach to this factor so much importance. It can be noted that members of this cluster almost equally prefer hostels located downtown and outside the center with good connection to the center. Furthermore, members of this cluster prefer hostels with homely or active atmosphere and friendly staff, although these characteristics are not crucial (Figure 5). 
M. Kuzmanović et al./Decis. Mak. Appl. Manag. Eng. 4 (2) (2021) 200-224

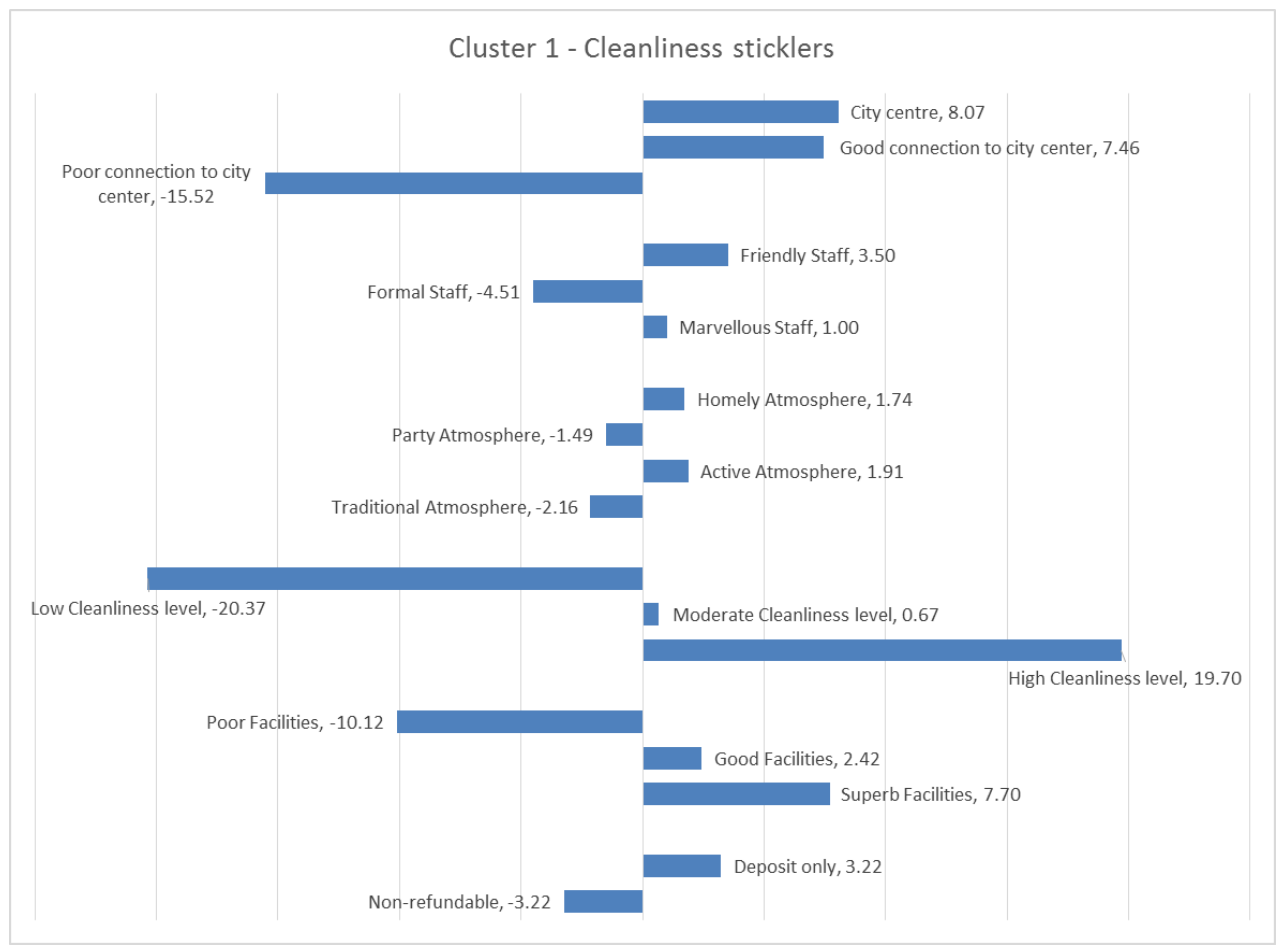

Figure 5. Cleanliness sticklers' preferences

A more detailed analysis has shown that this cluster consists mainly of female respondents (60\%), who are on average slightly older than respondents in the remaining two segments. Although most of them come from Europe, this percentage is lower than in the other two clusters, as can be seen in Figure 4. For respondents of this segment, the first choice when deciding on an accommodation is a hotel, while when choosing a hostel, the acceptable hostel rating is higher than for the other two groups.

\subsubsection{Cluster 2 - Location Demanders}

This cluster is the largest one ( $36 \%$ of the total sample) and is made up by respondents to whom location is by far the most important factor when choosing a hostel (relative importance of $45 \%$ ). Compared to the other two clusters, they much more prefer that hostel to be located in the city center, although they also largely accept a location with a good connection to the center (Figure 6). 
Incorporating heterogeneity of travelers' preferences into the overall hostel performance...

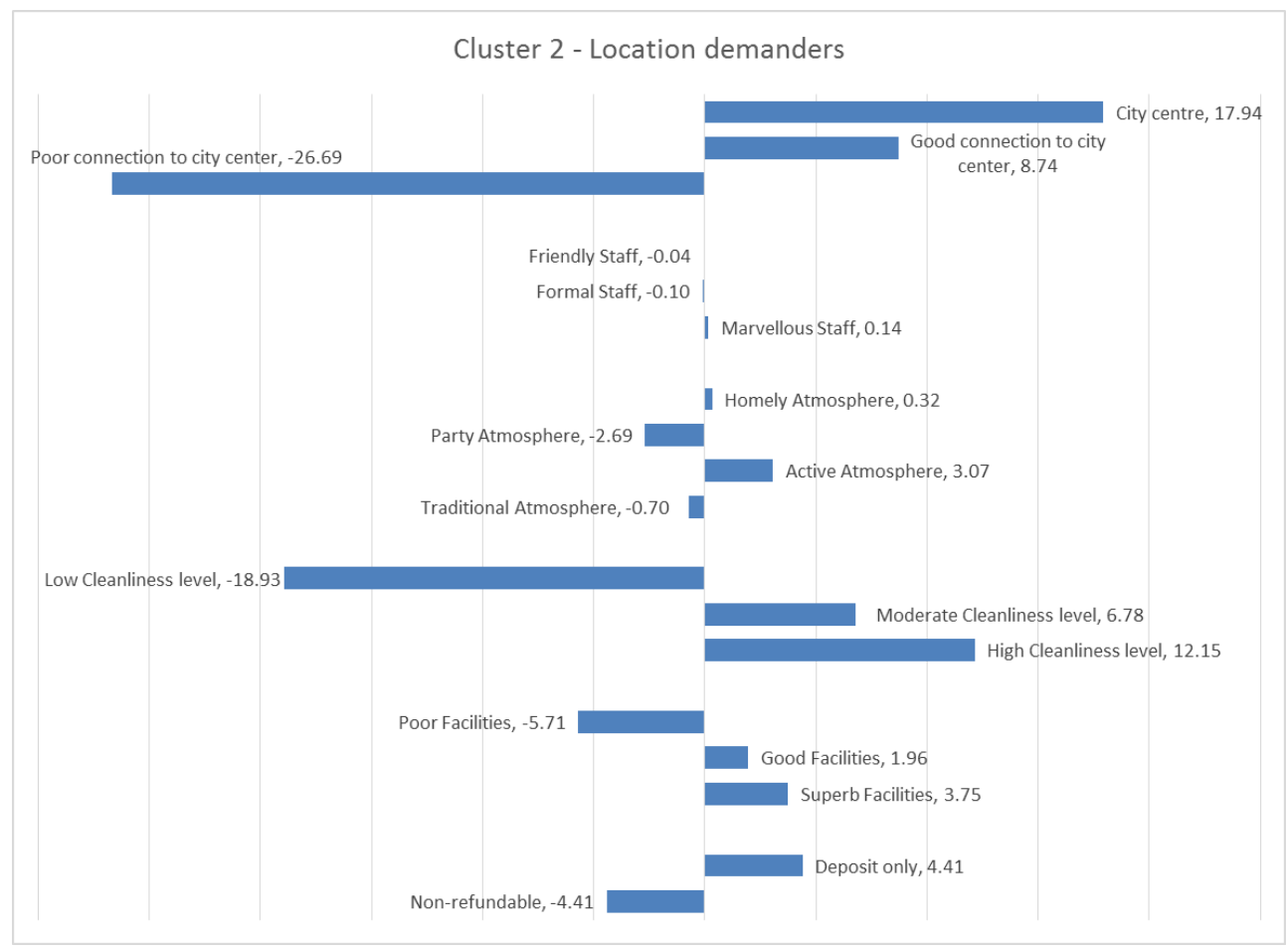

Figure 6. Location demanders' preferences

Another very important attribute for this group of respondents is cleanliness $(32 \%)$, while on the third place is the Cancellation policy with relative importance of $10 \%$ which is higher value than for the other two clusters. This cluster also significantly more prefers the moderate level of cleanliness than the previous one. Members of this cluster prefer the active and homely atmosphere, and superb or good facilities. The staff is the least important attribute for this cluster with an importance value of only $2 \%$. It is interesting that the utility of the level of marvelous staff has a negative sign, and that the respondents showed indifference towards formal staff.

The ratio of males and females is similar to that of the first cluster (58\% females). Average age of cluster members is 27.46 years and most of them are European (86\%). Compared to the "cleanliness sticklers", they accept a slightly lower average rating of the hostel, and to a large extent as the first choice of accommodation, next to the hotel, also quote Airbnb. It is interesting that $33 \%$ of respondents from this segment are unemployed or part-time employed.

\subsubsection{Cluster 3 - Party Seekers}

The third cluster is the smallest one and covers $26 \%$ of the sample. As with the previous cluster, this group of respondents give the highest importance to the attribute Location (36\%), whereby they most prefer to be located out of the downtown but with a good connection to it. Another interesting thing about this cluster is that the attribute Atmosphere is much more important for members compared to other clusters (importance value is 19\%). Respondents belonging to this group prefer hostels with the party atmosphere, while the traditional and active atmosphere reduce their overall preferences (the partial utilities of these levels have a negative sign, which can be seen in Figure 7). 


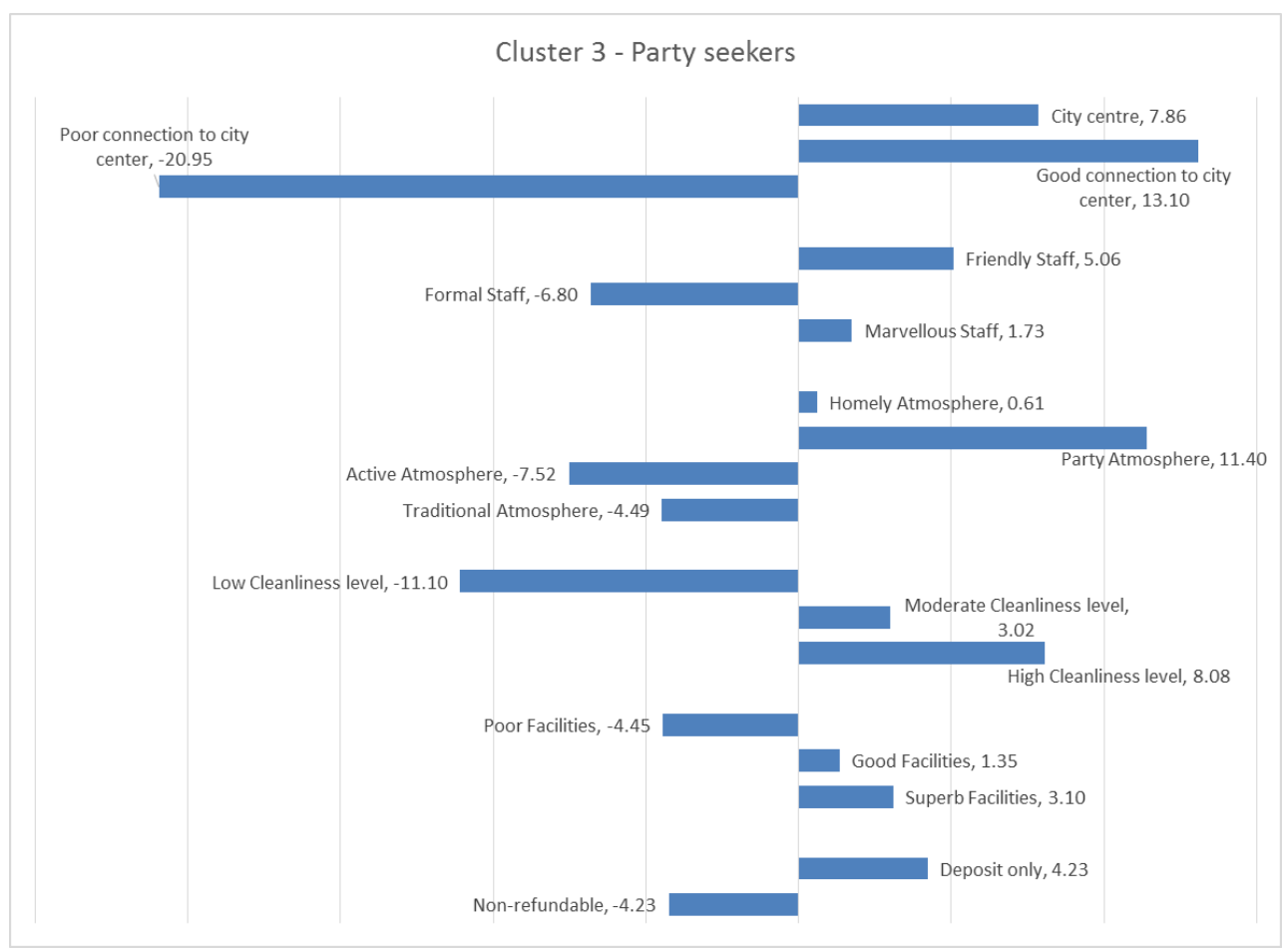

Figure 7. Party seekers' preferences

Cleanliness is the second most important factor with an importance value of $21 \%$, but it is significantly less important than in the other two clusters. The remaining three attributes - staff, facilities, and cancellation policy are of almost equal importance. This segment is the only one with more males than females (33 versus 30 ) and with the average age of 26.44 represent the youngest cluster. Even $84.13 \%$ of this group of individuals are single. It is interesting to point out that respondents from this cluster mostly stay in hostels when travelling ( $41.2 \%$ stated hostel as the first choice), and the hostel rating they find acceptable is slightly lower than for the other two segments.

\subsection{Simulation Results}

\subsubsection{Share of Preference Simulation}

Using part-worths of the attribute levels (Table 4) as input values, share of preference simulation was carried out. Let us assume that three hostels are currently available on the market (Scenario 1). Table 6 shows the description of these three hostels as well as their share of preferences.

In Scenario 1, the highest share of preferences goes to Hostel 2 (45.41\%), while Hostel 3 exhibits the lowest share of only $12.56 \%$. A certain number of respondents would not opt for any of the offered hostels, in fact 3.07\% of them (Table 6). Suppose that Hostel 1 considers to change policy of cancellation in order to achieve a higher share of preferences and improve its market position. The simulation results show that this action will result in significantly higher share of preferences, reaching $56.26 \%$, which makes this move justified. Also, the percentage of respondents who did not opt for any of the offered hostels in the first scenario was lower in the Scenario 2. 
Incorporating heterogeneity of travelers' preferences into the overall hostel performance...

Table 6. Share of preferences simulation

\begin{tabular}{|c|c|c|c|c|c|c|c|}
\hline & Location & Staff & Atmosphere & $\begin{array}{c}\text { Cleanliness } \\
\text { level }\end{array}$ & Facilities & $\begin{array}{c}\text { Cancellation } \\
\text { policy } \\
\text { (refund) } \\
\end{array}$ & $\begin{array}{l}\text { Share of } \\
\text { preference }\end{array}$ \\
\hline \multicolumn{8}{|c|}{ Scenario 1} \\
\hline Hostel 1 & City center & Friendly & Party & High & Good & $\begin{array}{l}\text { Non- } \\
\text { refundable }\end{array}$ & $38.97 \%$ \\
\hline Hostel 2 & $\begin{array}{l}\text { Good connection } \\
\text { to city center }\end{array}$ & Marvelous & Homely & High & Good & $\begin{array}{l}\text { Deposit } \\
\text { only }\end{array}$ & $45.41 \%$ \\
\hline \multirow[t]{2}{*}{ Hostel 3} & $\begin{array}{l}\text { Poor connection } \\
\text { to city center }\end{array}$ & Friendly & Active & High & Superb & $\begin{array}{l}\text { Deposit } \\
\text { only }\end{array}$ & $12.56 \%$ \\
\hline & None of the above & & & & & & $3.07 \%$ \\
\hline \multicolumn{8}{|c|}{ Scenario 2} \\
\hline Hostel 1 & City center & Friendly & Party & High & Good & $\begin{array}{l}\text { Deposit } \\
\text { only }\end{array}$ & $56.26 \%$ \\
\hline Hostel 2 & $\begin{array}{l}\text { Good connection } \\
\text { to city center }\end{array}$ & Marvelous & Homely & High & Good & $\begin{array}{l}\text { Deposit } \\
\text { only }\end{array}$ & $31.10 \%$ \\
\hline Hostel 3 & $\begin{array}{l}\text { Poor connection } \\
\text { to city center }\end{array}$ & Friendly & Active & High & Superb & $\begin{array}{l}\text { Deposit } \\
\text { only }\end{array}$ & $11.13 \%$ \\
\hline \multicolumn{2}{|c|}{ None of the above } & & & & & & $1.51 \%$ \\
\hline
\end{tabular}

Similar simulations can be performed for some other changes in hostel offerings, but it is also possible to simulate the share of preferences of a potential hostel that currently does not exist but is planning to run. Furthermore, the impact of the newly introduced hostel on the preference share of existing hostels on the market can also be simulated.

\subsubsection{Overall Weighted Hostel Rating}

As previously mentioned, a number of web portals offer guests the opportunity to evaluate hostels performance based on their key features. However, most estimates are based on a rating of each of the features individually from the set of features on the Likert scale. Evaluations of these features are then averaged to get the overall hostel performance score. This can greatly provide the wrong picture because not all features are equally important for all respondents. Thus, in this paper we suggest that the relative importance of the attributes are used as weights. This would make the valuations more realistic and would better reflect the real satisfaction of the respondents.

Let $b_{j k}$ be the respondents' rating for the $j$ th hostel according to the $k$ th criterion. The weights $W_{k}$ represent the feature importance obtained through DCA. Thus, the overall weighted score of the $j$ th hostel is calculated as follows:

$W R_{j}=\sum_{k=1}^{K} W_{k} b_{j k}, \quad j=1, \ldots, J$

The advantages of the proposed approach will be presented on the example of four hypothetical hostels (see Table 7). For each of the hostels, the ratings are given according to six features. Averaged performance scores for all of these hostels is equal to 4 , and it seems that they are equally good perceived (well-seen) by guests, but the question is whether it is really so. Namely, some hostels with qualitatively different features achieve the same average score, indicating a weak discriminatory power of average-based approach.

Table 7 also presents the overall ratings obtained by the approach we proposed, which implies multiplying the ratings assigned to an individual hostel feature by the value of the feature importance to produce a weighted score. The results show that 
M. Kuzmanović et al./Decis. Mak. Appl. Manag. Eng. 4 (2) (2021) 200-224

there are clear differences in overall ratings of the hostel. It is especially interesting to compare Hostel 3 and Hostel 4 scores, where both hostels are rated by the same set of ratings, but these are assigned to different criteria. Although the average scores are the same, the difference in the overall ratings is high and reaches a value of almost one.

Table 7. Averaged versus weighted averaged overall hostel ratings

\begin{tabular}{c|ccccc}
\hline Features & Feature & Hostel & Hostel & Hostel & Hostel \\
& weight & 1 & 2 & 3 & 4 \\
\hline Location & 0.340 & 4 & 4 & 3 & 5 \\
Staff & 0.064 & 4 & 4 & 5 & 3 \\
Atmosphere & 0.034 & 4 & 3 & 5 & 3 \\
Cleanliness level & 0.353 & 3 & 4 & 3 & 5 \\
Facilities & 0.128 & 5 & 4 & 5 & 3 \\
Cancellation policy (refund) & 0.081 & 4 & 5 & 3 & 5 \\
Average & & $\mathbf{4}$ & $\mathbf{4}$ & $\mathbf{4}$ & $\mathbf{4}$ \\
Weighted average & & $\mathbf{3 . 7 8}$ & $\mathbf{4 . 0 5}$ & $\mathbf{3 . 4 5}$ & $\mathbf{4 . 5 5}$ \\
\hline
\end{tabular}

\section{Discussion and Conclusions}

\subsection{Key findings of the study}

Bearing in mind that the hostel market is rapidly developing by increasing its diversity, and that it attracts a growing number of guests, usually Millennials, but also investors, it is not surprising that the number of studies related to this market is also on the rise. In order for a hostel business to be sustainable, all three goals, namely economic, social and environmental, need to be addressed.

As both the social and economic dimensions of a sustainable hostel business are conditioned by guest satisfaction, it is clear that understanding what guests expect to experience in a hostel is the best way to achieve it. To reveal travelers' habits and preferences for the factors they consider when choosing hostel accommodation, we conducted a survey. In a sample of 218 respondents, hostels occupy a significant second place when it comes to the type of accommodation they most stay in, which is in line with other studies. It was also found that most respondents book accommodation online, which is consistent with Phocusvright report (2018). However, Airbnb and other P2P platforms have been shown to be a threat to the hostel market, primarily because of the price, location and convenience of accommodation they offer, but also because they strongly promote social, economic and environmental sustainability (Gössling \& Michael, 2019).

There are a number of research studies that have explored the motives of the traveler and the impact of different hostel characteristics on the choice of hostels, but they are mostly based on direct assessment of these characteristics individually. Fewer research was done on the topic of how much users are willing to trade a certain hostel feature for another (Kim \& Park, 2017). In this study, we used discrete choice analysis, a method that measures guests' individual preferences allowing them to make trade-offs between attributes such as cleanliness, location, staff, atmosphere, facilities, and cancellation policy.

When it comes to the most important attributes, cleanliness and location, our findings are in line with the findings of many other studies as stated in the literature review. However, although all of the listed studies have also identified these two 
Incorporating heterogeneity of travelers' preferences into the overall hostel performance...

factors as very important, our study provides a clearer distinction of attributes in terms of the intensity of their influence on the choice of hostel. When it comes to facilities, numerous studies have highlighted the importance of this attribute for guest satisfaction. In our study, this attribute is third ranked, but its relative importance is almost three times lower than the importance of the two best ranked attributes. Furthermore, other studies did not consider the cancelation policy as the attribute that affect individuals' choice of hostel. Our results have shown that this attribute is, on average, more important than the attributes of staff and atmosphere. It may be surprising that the staff is considerably less important attribute than cleanliness and location, even by about five times, as it contradicts the findings presented in (Lima and Vicente, 2017; Martins et al., 2018). Similarly, the atmosphere has less impact on hostel choice than cleanliness and location, for more than six times.

The results also indicate that hostel guests are not a homogeneous group, pointing to the importance of revealing preferences of subgroups of travelers. The results of post hoc clustering clearly indicated differences in the three groups of respondents, which were not noticeable in an a priori segmentation. Although cleanliness and location are high-ranking attributes in all three clusters, their impact on overall preferences is not the same. Actually, some attributes that were significantly less important on the aggregate level, proved to be more important in some clusters. So, Facilities and Atmosphere attributes, with a relative importance of $19 \%$ each, are third-ranked ones among Cleanliness Sticklers and Party Seekers, respectively. Also, the Cancellation Policy attribute ranks third in the Location Demanders cluster, with a relative importance of $10 \%$.

By performing simulations, we have shown that the results can be used for the decision making under uncertainty, in particular, to determine how the potential market share will change by changing some of the attribute levels, whether its own or those of the competitors.

\subsection{Implications, Limitations and Future Work}

The theoretical implications of our study are reflected in the enrichment of the literature related to hostel stay motives and factors affecting guest preferences and satisfaction. As the impact of a hostel as a business model on the sustainability of the economy and society is reflected in higher consumption, greater employability, economic development of cities, regions, and even countries, the study findings have important implications for various stakeholders in tourism industry as well.

Study results may be useful for hostels to improve their service and increase their competitive advantage, but also for those who are considering investing in a sustainable hostel in the future. For example, in order to improve environmental performance, hostels should provide eco-friendly facilities to the first cluster (Cleanliness Sticklers) in addition to high cleanliness. Given that the same cluster prefers an active atmosphere and agree to a location outside the city center, the possibility to rent a bike for free is another option that could have a positive effect on the environment. The satisfaction of these respondents would be even greater with friendly staff who could promote various social and ecological activities such as local sightseeing/attractions within walking distance. Similar applies to the cluster of location demanders. For the third cluster (party seekers), hostels could organize green parties that could also become a trademark of hostel.

The managers of hostel booking websites could use the results of this study to create a proper list of factors that guests could evaluate, but also to better understand the influences of those factors on the overall guests' perception of a particular hostel. Because hostel online reviews can be used for sustainable strategic marketing 
decisions against competitors it is important that guests have the opportunity to evaluate the hostel's environmental performance as well.

However, our study has its limitations. First, not all aspects of a sustainable business model, such as the environmental one, have been considered. Second, because of the sampling method used, the data collected may be biased and reflect the preferences of the study participants rather than the entire population. As the popularity of hostels is growing among family people and is increasingly being used for accommodation on business trips, to make the results more credible, the sample should also include those respondents who less use modern technology, social networking sites or forums, but also older respondents. Third, the size of the sample itself could be more extensive by including significantly more respondents outside the European continent.

Regardless of the limitations, this study can be a good starting point for upgrading and drawing more general conclusions. Future research could be directed towards conducting a survey that would cover a broader population and address all three pillars of a sustainability: economic, social and environmental. In this way, it would be possible to identify the respondents' preferences for each of the pillars, as well as to determine trade-offs that both businesses and tourists are willing to make in terms of giving up one sustainability component for another.

Author Contributions: Each author has participated and contributed sufficiently to take public responsibility for appropriate portions of the content.

Funding: This research received no external funding.

Conflicts of Interest: The authors declare no conflicts of interest

\section{References}

Amblee, N. (2015). The impact of cleanliness on customer perceptions of security in hostels: A WOM-based approach. International Journal of Hospitality Management, 49, 37-39, doi:10.1016/j.ijhm.2015.04.011.

Ban, H.J., Choi, H., Choi, E.K., Lee, S., \& Kim, H.S. (2019). Investigating Key Attributes in Experience and Satisfaction of Hotel Customer Using Online Review Data. Sustainability, 11(23), 6570, doi:10.3390/su11236570

Belz, F.M., \& Binder, J.K. (2017). Sustainable entrepreneurship: A convergent process model. Business Strategy and the Environment, 26(1), 1-17, doi:10.1002/bse.1887.

Ben-Akiva, M., McFadden, D., \& Train, K. (2019). Foundations of stated preference elicitation: Consumer behavior and choice-based conjoint analysis. Foundations and Trends ${ }^{\circledR}$ in Econometrics, 10(1-2), 1-144, doi: 10.1561/0800000036.

Ben-Akiva, M.E., \& Lerman, S.R. (1985). Discrete choice analysis: theory and application to travel demand, Volume 9. MIT press. 1985.

Brochado, A., Rita, P., \& Gameiro, C. (2015). Exploring backpackers' perceptions of the hostel service quality. International Journal of Contemporary Hospitality Management, 27(8), 1839-1855, doi:10.1108/IJCHM-03-2014-0145. 
Incorporating heterogeneity of travelers' preferences into the overall hostel performance...

Capitello, R., Agnoli, L., Charters, S., \& Begalli, D. (2017). Exploring place image from visitors' expected and lived experiences: A discrete choice approach. Journal of Customer Behaviour, 16(1), 19-34, doi:10.1362/147539217X14909732699462.

Cave, J., Thyne, M., \& Ryan, C. (2008). Perceptions of backpacker accommodation facilities: a comparative study of Scotland and New Zealand. In Backpacker tourism: Concepts and profiles (pp. 215-246), Hannam, K., Atelievic, I. Eds.;. Channel View Publications: Clevedon, 2008.

Chang, K., Chien, H., Cheng, H., \& Chen, H.I. (2018). The Impacts of Tourism Development in Rural Indigenous Destinations: An Investigation of the Local Residents' Perception Using Choice Modeling. Sustainability, 10(12), 4766, doi:10.3390/su10124766

Chitty, B., Ward, S., \& Chua, C. (2007). An application of the ECSI model as a predictor of satisfaction and loyalty for backpacker hostels. Marketing Intelligence \& Planning, 25(6), 563-580, doi:10.1108/02634500710819941.

Cró, S., \& Martins, A.M. (2017). The importance of security for hostel price premiums: European empirical evidence. Tourism Management, 60, 159-165, doi:10.1016/j.tourman.2016.11.021.

de Bekker-Grob, E.W., Donkers, B., Jonker, M.F., \& Stolk, E.A. (2015). Sample size requirements for discrete-choice experiments in healthcare: a practical guide. The Patient-Patient-Centered Outcomes Research, 8(5), 373-384.

de Oliveira Santos, G.E. (2016). Worldwide hedonic prices of subjective characteristics of hostels. Tourism Management, 52, 451-454, doi:10.1016/j.tourman.2015.07.001.

Eugenio-Martin, J.L., \& Inchausti-Sintes, F. (2016). Low-cost travel and tourism expenditures. Annals of Tourism Research, 57, 140-159.

Farr, C, 2020. When will we start traveling again? Here's what experts are saying. https://www.cnbc.com/2020/05/05/when-will-travel-resume-

aftercoronavirus.html. Accessed on 18 May 2020.

González, R.M., Marrero, Á.S., \& Navarro-Ibáñez, M. (2018). Tourists' travel time values using discrete choice models: the recreational value of the Teide National Park. Journal of Sustainable Tourism, 26(12), 2021-2042. doi:10.1080/09669582.2018.1527342

Gössling, S., \& Michael Hall, C. (2019). Sharing versus collaborative economy: how to align ICT developments and the SDGs in tourism?. Journal of Sustainable Tourism, 27(1), 74-96. doi: 10.1080/09669582.2018.1560455.

Hecht, J.A., \& Martin, D. (2006). Backpacking and hostel-picking: an analysis from Canada. International Journal of Contemporary Hospitality Management, 18(1), 69-77. doi:10.1108/09596110610641993.

Hory, G., Major, Z., Müllner, P., \& Benko, M. (2017). Exploration of spatial design issues at backpacker hostels in Budapest' s historic center: Informality, density, and adaptability. Frontiers of architectural research, 6(2), 157-168, doi:10.1016/j.foar.2017.02.005.

Kim, D., \& Park, B. (2017). The moderating role of context in the effects of choice attributes on hotel choice: A discrete choice experiment. Tourism Management, 63, 439-451, doi:10.1016/j.tourman.2017.07.014. 
M. Kuzmanović et al./Decis. Mak. Appl. Manag. Eng. 4 (2) (2021) 200-224

Kuzmanovic, M., \& Savic, G. (2020). Avoiding the Privacy Paradox Using PreferenceBased Segmentation: A Conjoint Analysis Approach. Electronics, 9(9), 1382. doi: 10.3390/electronics 9091382

Kuzmanovic, M., Makajic-Nikolic, D., \& Nikolic, N. (2020). Preference based portfolio for private investors: Discrete choice analysis approach. Mathematics, 8(1), 30, doi:10.3390/math8010030.

Lemus-Aguilar, I., Morales-Alonso, G., Ramirez-Portilla, A., \& Hidalgo, A. (2019). Sustainable Business Models through the Lens of Organizational Design: A Systematic Literature Review. Sustainability, 11(19), 5379, doi:10.3390/su11195379

Lima, R., \& Vicente, P. (2017) Exploring the relationship between hostel service quality and guests' satisfaction: a comparison between younger and older guests. $e R T R, 5-6$, 242-257.

Lin, Y. C., Chen, T., \& Wang, L. C. (2018). Integer nonlinear programming and optimized weighted-average approach for mobile hotel recommendation by considering travelers' unknown preferences. Operational Research, 18(3), 625-643.

Mangham, L.J., Hanson, K., \& McPake, B. (2009). How to do (or not to do)... Designing a discrete choice experiment for application in a low-income country. Health policy and planning, 24(2), 151-158, doi:10.1093/heapol/czn047.

Martins, M.R., Rachão, S., \& Costa, R.A.D. (2018). Electronic word of mouth: Does it really matter to backpackers? Booking website reviews as an indicator for hostels' quality services. Journal of Quality Assurance in Hospitality \& Tourism, 19(4), 415-441, doi:10.1080/1528008X.2018.1429980.

Mihalic, T. (2014). Tourism and Economic Development Issues. In Tourism and Development. Concepts and Issues, 2nd ed. (pp. 77-117), Sharpley, R., Telfer, D., (Eds.), Channel View Publications: Toronto.

Muñoz-Fernández, G., Sánchez-Cañizares, S., \& Infante, S. (2016). Youth and Tourism Perspective. Application to Hostels. Regional and Sectoral Economic Studies, 16(1), 7188.

Musa, G., \& Thirumoorthi, T. (2011). Red Palm: exploring service quality and servicescape of the best backpacker hostel in Asia. Current Issues in Tourism, 14(2), 103-120, doi:10.1080/13683500903511125.

Nash, R., Thyne, M., \& Davies, S. (2006). An investigation into customer satisfaction levels in the budget accommodation sector in Scotland: A case study of backpacker tourists and the Scottish Youth Hostels Association. Tourism Management, 27(3), 525532, doi:10.1016/j.tourman.2005.01.001.

Nguyen, P. T. (2020). The future of budget accommodation post COVID-19: Case study: Cheapsleep Hostel Helsinki, LAB University of Applied Sciences, https://www.theseus.fi/bitstream/handle/10024/346773/Thesis\%20$\% 20$ Tai\%20Nguyen.pdf?sequence=2\&isAllowed $=y$

Norris, G., Qureshi, F., Howitt, D., \& Cramer, D. (2014). Introduction to Statistics with SPSS for Social Science; Routledge. 
Incorporating heterogeneity of travelers' preferences into the overall hostel performance...

O'Regan, M. (2010). Backpacker Hostels: Place and Performance. In Beyond backpacker tourism: Mobilities and experiences (pp. 85-102); Hannam, K., Diekmann, A.; Channel View Publications: Bristol, UK.

Oliveira-Brochado, A., \& Gameiro, C. (2013). Toward a better understanding of backpackers' motivations. Tékhne, 11(2), 92-99, doi:10.1016/j.tekhne.2013.11.001.

Oppewal, H., Huybers, T., \& Crouch, G.I. (2015). Tourist destination and experience choice: A choice experimental analysis of decision sequence effects. Tourism Management, 48, 467-476, doi:10.1016/j.tourman.2014.12.016.

Orme, B. (2010). Getting Started with Conjoint Analysis: Strategies for Product Design and Pricing Research, 2nd ed., Research Publishers LLC: Madison.

Phocuswright. The Global Hostel Marketplace 2016-2020 Second Edition, 2018. Available online: https://www.phocuswright.com/Travel-Research/ConsumerTrends/The-Global-Hostel-Marketplace-2016-2020-Second-Edition (accessed on 26 October 2020)

Popović, M., Kuzmanović, M., \& Savić, G. (2018). A comparative empirical study of Analytic Hierarchy Process and Conjoint analysis: Literature review. Decision Making: Applications in Management and Engineering, 1(2), 153-163. doi:10.31181/dmame1802160p

Puška, A., Pamucar, D., Stojanović, I., Cavallaro, F., Kaklauskas, A., \& Mardani, A. (2021). Examination of the Sustainable Rural Tourism Potential of the Brčko District of Bosnia and Herzegovina Using a Fuzzy Approach Based on Group Decision Making. Sustainability, 13(2), 583.

Rakotonarivo, O.S., Schaafsma, M., \& Hockley, N. (2016). A systematic review of the reliability and validity of discrete choice experiments in valuing non-market environmental goods. Journal of Environmental Management, 183, 98-109, doi:10.1016/j.jenvman.2016.08.032.

Rossi, P., Allenby, G., \& McCulloch, R. (2012). Bayesian statistics and marketing. John Wiley \& Sons.

Roy, J., Kumar Sharma, H., Kar, S., Kazimieras Zavadskas, E., \& Saparauskas, J. (2019). An extended COPRAS model for multi-criteria decision-making problems and its application in web-based hotel evaluation and selection. Economic researchEkonomska istraživanja, 32(1), 219-253.

Veríssimo, M., \& Costa, C. (2018). Do hostels play a role in pleasing Millennial travellers? The Portuguese case. Journal of Tourism Futures, 4(1), 57-68, doi:10.1108/JTF-12-2017-0054.

Vukic, M., Kuzmanovic, M., \& Kostic Stankovic, M. (2015). Understanding the heterogeneity of generation y's preferences for travelling: A conjoint analysis approach. International Journal of Tourism Research, 17(5), 482-491., doi:10.1002/jtr.2015.

World Travel and Tourism Council (2018). Travel and tourism economic impact 2018: World.; World Travel and Tourism Council: London. 
M. Kuzmanović et al./Decis. Mak. Appl. Manag. Eng. 4 (2) (2021) 200-224

(C) 2021 by the authors. Submitted for possible open access publication under the terms and (c) (i) conditions of the Creative Commons Attribution (CC BY) license (http://creativecommons.org/licenses/by/4.0/). 